\title{
An Investigation of Differences in Student Success and Persistence Rates by Course Modality
}

\author{
Celisa Counterman ${ }^{1}$, Linda R Zientek ${ }^{2 *}$ \\ ${ }^{1}$ Northampton Community College, Bethlehem, PA, USA \\ ${ }^{2}$ Department of Mathematics \& Statistics, Sam Houston State University, Huntsville, TX, USA \\ * Corresponding author: Irzientek@shsu.edu
}

Received: 13 Apr. 2021 Accepted: 31 May 2021

Citation: Counterman, C., \& Zientek, L. R. (2021). An Investigation of Differences in Student Success and Persistence Rates by Course Modality. European Journal of Science and Mathematics Education, 9(3), 110-124. https://doi.org/10.30935/scimath/10976

\begin{abstract}
:
Emporium courses have been offered as an option to reduce the amount of time students spend in developmental mathematics courses. This study investigated differences in achievement and persistence in mathematics by course modality for students enrolled in developmental mathematics at a suburban community college in the Northeast United States from fall 2015 through spring 2019. Statistically significant differences existed in final exam score and course grades by course level. For the upper two developmental mathematics courses, achievement measures in emporium courses were comparable to face-to-face courses. Thus, an emporium model that is designed to provide a semi-structured schedule, prompt feedback, and frequent interactions with tutors and faculty is a viable option for middle- and upperlevel courses. The emporium modality did not appear to benefit students placed into the lowest level course (i.e., prealgebra) as grades and persistence rates were lower compared to face-to-face courses. Online course modality was not the best option across all course levels. The results of this study may have implications for post-secondary institutions that want to begin offering developmental mathematics courses in multiple modalities.

Keywords: course redesign, persistence, success, developmental mathematics, course modality
\end{abstract}

\section{INTRODUCTION}

In the United States, developmental mathematics (DM) courses provide opportunities for underprepared college students to prepare for college coursework. Low success rates and the need for many students to complete multiple DM courses created a movement to redesign existing DM programs. Post-secondary educators, administrators, and policymakers sought to decrease the cost of serving these underprepared students (Lucas \& McCormick, 2007). One option was to offer multiple course modalities. Emporium models save time and money by offering students an opportunity to accelerate through the course sequence. Students only cover topics not already mastered. This counters the traditional face-to-face $(\mathrm{FtF})$ introductory-level mathematics mode that requires students to cover all topics in a course. This study sought to determine the extent to which the implementation of a DM emporium course was successful compared to online and FtF courses, regarding student success and persistence rates.

While an open-door policy at community colleges provides equitable opportunities, an outcome has been high enrollment numbers in remedial courses, particularly in mathematics (Chen \& Simone, 2016). Higher enrollment in DM compared to reading and writing has often targeted mathematics as a barrier course with many students completing upwards of three remediation courses. Because of high enrollment numbers, high failure rates, and multiple courses required, the success of developmental 
education programs has been called into question (Bahr, 2008). Chen and Simone (2016) reported that $59 \%$ of students who began their post-secondary education in 2003-04 at a public 2-year institution enrolled in a DM course with only $50 \%$ ever completing the sequence.

The need to complete multiple remedial courses for no credit seems insurmountable to some students; thus, compressed and accelerated models have been implemented by some institutions to increase student success and retention rates (Cafarella, 2016). Some states began mandating options that provide opportunities for students to accelerate through the developmental content (Rutschow \& Schneider, 2011). Offering alternative delivery modalities allows students to spend less time in and money on developmental courses. This study focused on the emporium model, which is an accelerated course option that allows students to focus their remediation only on the mathematics skills they are deficient in instead of completing an entire course. Because the delivery of emporium courses has been recent, rigorous research has been lacking; in terms of the effects, these reforms have had on student achievement (Rutschow \& Schneider, 2011). The purpose of this study was to help fill that research void by comparing success and persistence rates of students who completed an emporium DM course sequence with students who completed DM with the same content in a traditional FtF or online setting.

\section{CONCEPTUAL FRAMEWORK}

The conceptual framework of this study focused on the premise that emporium models might increase students' success and persistence in mathematics through the acquisition of mastery experiences, use of self-regulatory strategies, and interaction with faculty and tutors, all while students receive prompt feedback in the online system and from tutors. An accelerated path also might increase motivation to persist as students can see completion of courses within a shorter timeframe than completion of traditional course sequence by testing out of content covered in multiple courses. In many colleges, students who have enrolled in emporium courses place into a set of modules and complete the modules for their specific degree. That means students only complete modules of materials they have not tested out of (Northern Virginia Community College, 2020). At the participating college, a computer-assisted instructional component was used in the emporium classroom. Students were required to work in a lab for a specific number of hours a week with their progress monitored by their faculty member. Multiple formative assessments and prompt feedback provided from the instructor or tutors helped students progress at an accelerated rate. The expectation for this modality was high, as students with the most deficits in mathematical knowledge might be expected to become college ready within one semester, compared to the traditional one to three semesters.

While emporium models can accelerate the time required to complete DM content, challenges exist and recommendations for effective models have been provided. Bickerstaff et al. (2016) found that the pacing of an accelerated course can be too fast for some students, which makes it challenging to catch up once they fall behind. Saxon and Martirosyan (2017) surveyed faculty and found that, while accelerating courses in mathematics have benefits for some students, courses must have a clearly defined structure, accurate placement, clear expectations, and proper advisement. In this study, emporium students worked at their own pace but had to meet some set timelines.

\section{Improved Affective Measures}

Even though affective measures were not studied, we hypothesized that the emporium model possibly holds the promise of improving affective measures through increased mastery experiences, reduced mathematics anxiety levels, and improved self-regulated learning strategies. The emporium course structure is built on an expectation that students demonstrate mastery of content. Mastery experiences have been touted as the most powerful source of self-efficacy (Usher \& Pajares, 2009; Zientek et al., 2019). Our hypothesis is supported by Taylor's (2008) results. Taylor (2008) found students in an emporium setting exhibited lower mathematics anxiety levels and better attitudes towards mathematics, in general, compared to students in a traditional FtF setting. In an emporium model, 
successful students demonstrate academic mastery as determined by reaching a benchmark grade on a proficiency exam. This is different than a traditional course where students can take a test and continue the course without demonstrating mastery of each topic. In a traditional course, a student could fail questions on adding fractions and still receive a passing course grade without demonstrating mastery of that content. Mastery is demonstrated in emporium courses as students are tested more frequently on smaller amounts of information and then reach a grade threshold before moving onto new materials.

Zimmerman (2005) defined self-regulated learning as the planning and adoption of an achievement goal, where a person's thoughts and feelings play an integral part. In emporium courses, students must (a) monitor their progress without an instructor standing in class laying out the calendar and lesson benchmarks that should be met for the day, (b) have more responsibility for modifying their learning methods and planning their goals, and (c) be their own driving motivator to complete assignments early to progress to the next course faster. As students can be at various stages in the course throughout, motivation to continue would be based on their own mastery criteria rather than that of other students in the course meaning students are using self-regulated learning strategies (Zimmerman, 1990).

\section{Classroom Practices in Emporium Courses}

Emporium courses provide opportunities for students to have frequent individualized contact with instructors, receive immediate feedback, and set high expectations. Those opportunities correspond to three of Chickering and Gamson's (1987) seven principles for classroom practices that can increase a students' engagement and persistence.

\section{Engagement through interaction with faculty}

Chickering and Gamson (1987) reported that student-faculty contact was "the most important factor in student motivation and involvement" (p. 3). Students in emporium courses in this study had ondemand individual assistance from faculty and professional tutors in the classroom during open lab periods and could not proceed in the course without speaking with them at various stages of the course. For example, students who were on the cusp of a mastery grade or needed to retake an assessment had to meet with the faculty member to get approval and therefore had engagement through interaction with that instructor. The frequent student-faculty interaction was a valued component of the emporium course as students informally interacted with faculty while the faculty walked around to help students as they worked on the computer. Twigg's (2011) study found that, in emporium courses, the most vulnerable students received more individualized support and assistance, as faculty members had the time to respond to their immediate questions and needs. In regard to cognitive engagement, no assumption can be made that students in an emporium model were more cognitively engaged than students in a FtF or online classroom or just engaged in completing the modules to move to the next class.

\section{Prompt feedback}

Emporium students received prompt feedback, which is considered a positive educational practice (Chickering \& Gamson, 1987). Feedback offers students the chance to organize their studies and learn from their errors. Emporium students received immediate feedback from online assessments, faculty, and embedded classroom tutors. Instructors could readily identify content students were not mastering. This format kept students actively engaged to acquire their own knowledge (Cousins-Cooper et al., 2017) and allowed opportunities for faculty to work during class time with individuals or small groups.

\section{High expectations through mastery learning}

A variety of factors can influence student success, including expectations and influences of families, peer groups, and faculty members. High expectations can benefit students who are unmotivated or underprepared, as well as high achieving students (Chickering \& Gamson, 1987). In the emporium model, high expectations are set by students as they endeavor to accelerate through course material and 
demonstrate mastery of topics. For emporium courses, high expectations were manifested through the achievement benchmarks that were required before moving to the next section. However, this does not mean that high expectations were not set in other course modalities, as well.

\section{Course Delivery Modalities}

Traditionally, DM education consisted of multiple courses that served as pre-requisites for gateway courses such as statistics and college algebra. The traditional DM course sequence seemed to impede students' ability to continue to the college-level courses (Bailey et al., 2010). While this study focused on $\mathrm{FtF}$, emporium, and online course formats, this study did not focus on changes in curriculum because delivery methods often do not focus on curriculum changes.

\section{Traditional face-to-face modalities}

Traditionally, students enrolled in introductory-level mathematics classrooms at community colleges have been taught in FtF settings. Many students will choose FtF courses because it is what they are most comfortable with, having learned in that manner for much of their academic lives. In a study by Ashby et al. (2011), many younger college students still seemed to select traditional FtF courses. In the traditional FtF setting, research suggests that community college students have been primarily taught via lecture (Mesa et al., 2014). Little time for in-class homework is normally provided.

Today, teachers have been encouraged to incorporate active learning strategies. FtF courses have benefits when students have opportunities to learn from each other. Student interaction on group projects can encourage peer learning. Questions asked by peers help students learn and can help them realize holes in their own learning. The promotion of active learning strategies such as think-pair-share, clickers, inquiry-based learning, and projects have added benefits. For example, active learning in the form of think-pair-share in lecture courses encourages classroom participation. Emporium students participate in active learning as they "spend most of their time actively engaging with course content through a range of tasks" (Braun et al., 2017, p. 126). Furthermore, using active learning strategies "allows faculty to be more responsive to students' misunderstandings, which in turn causes students to feel more supported in the course, frequently leading to increased engagement" (Braun et al., 2017, p. 126). These student-centered instructional tools help students expand their own learning by providing multiple opportunities for partnerships in the classroom with their peers and faculty to engage in learning.

\section{Online settings}

Increases in technology in the 1990s led to the evolution of online courses. Computer-aided software made collecting and grading homework easier for faculty and students (Cafarella, 2014). In online courses, students typically are not tied to a specific classroom time or setting (i.e., asynchronous) and can work ahead if desired, although the instructor usually mandates a schedule. Students rarely, if ever, meet with their instructor or other students. This format allows students to work around family and work obligations with decreased costs of transportation and childcare. Feedback can often be more detailed and focused on each student $(\mathrm{Ni}, 2013)$. Some students learn better time management skills and become better independent thinkers in online formats (Cafarella, 2014). Learning materials tend to be presented in a virtual folder that may include readings, notes, videos, slide presentations, homework, and other assessment tools like discussion boards (Ashby et al., 2011). Interactive tools, like chat rooms or discussion boards, may help students with difficult concepts and foster interactivity. Research findings on online courses have been conflicting with some studies finding students in online courses are more successful than students in brick-and-mortar lecture classes (Nguyen, 2015) while other studies finding that students in online courses withdrawal at higher rates mid-semester than their counterparts in a lecture course (Xu \& Jaggars, 2013). 


\section{Emporium courses}

In emporium courses, students work at their own pace, albeit with deadlines and with an instructor nearby who serves more as a tutor or coach. Students learn with the assistance of computer software that is personalized and on-demand (Twigg, 2011). The software allows students to work independently on specific skills deficits identified by the program through content and frequent assessments of their abilities (Rutschow \& Schneider, 2011). Students can by-pass content they have demonstrated mastery on via a pre-test and concentrate on material they struggle with by using individualized study plans (Twigg, 2011). Mastery must be demonstrated on a topic before moving to the next topic, as measured by benchmark scores on short assessments. If a student does not complete the course on time, the emporium model student can pick up the next semester where they finished, whereas the FtF and online courses students who fail must start from the beginning of the course each semester (Fain, 2011). Successful emporium models utilized workstations, tables, and commercial software programs to lower the costs of development. Tables and workstations allow students to work collaboratively and receive just-in-time remediation on specific topics. Software allows for active learning as students are actively engaged with the content through a variety of tasks (Braun et al., 2017).

\section{Similarities between emporium and online courses}

More so than traditional FtF courses, similarities exist between emporium and online courses. In emporium and online courses, students spend time filling in notes, watching videos, reading PowerPoints, reading the textbook, and completing online homework, quizzes, and exam assessments. Students work independently, but emporium students see their classmates in a classroom setting, whereas online students communicate primarily in an online setting. Emporium students also have an immediate connection to their professor or tutors, whereas online students might need to wait for their communication for a variable amount of time.

\section{Course Modality for This Study}

Knowing the structure of the course modalities offered at the participating college is important to understanding this study. The number of emporium, $\mathrm{FtF}$, and traditional courses varied from semester to semester. There was an attempt by the college to keep the same number of each type of course from semester to semester for continuity. The quantity of each course offering was dictated by enrollment numbers each semester. Because students chose the course section that they wanted to enroll in, they chose their course modality.

\section{Emporium course}

In the emporium courses, FtF instruction was replaced with computers, and course content was organized in modules or chapters with specific due dates. Students worked problems in Pearson's MyLabsPlus system and were encouraged to complete guided note packets. Each emporium section met in a computer lab two or three days a week for 50-75 minutes per class. A faculty member and two tutors were in the classrooms to facilitate learning and solve software issues. The course structure was designed to keep students on track. Students began each module with a Skills Check that allowed them to either by-pass content if they scored an $85 \%$ or higher, or remove content from the corresponding homework, still allowing for acceleration. For each module, students completed homework, took a quiz, and then took an exam. When stumped on a problem in the classroom or an open lab, an emporium student had access to immediate help from tutors and faculty members. Students needed to attain an $85 \%$ on their homework before a corresponding quiz would open. Infinite opportunities were provided for students to improve their scores on their homework, and no points were taken off for missing a deadline. Students worked independently with one-on-one assistance that was given when requested. When a faculty member or tutor saw that multiple students were challenged by a concept, they conducted small breakout sessions in the classroom to bring those students together to foster collaborative work and clear up the discrepancies. Faculty members reviewed incorrect exam questions with students in order to help them work on areas of weakness. Unsuccessful students in this setting 
received additional resources to improve their knowledge base, which included additional worksheets, time in the learning center, or time in the math lab.

Quizzes were non-proctored assessments of content knowledge in that module. Students had two initial attempts on a quiz and could not continue to an exam until they had obtained a mastery score of at least $73 \%$ on that specific module quiz. Students who did not attain mastery worked with a faculty member and/or tutors before another attempt on the quiz was given. Work on both the homework and quizzes could be completed outside of the classroom time, but all exams were proctored on campus in the math lab. Exams also needed mastery of $73 \%$ before the next homework module would open. If students failed to achieve $73 \%$ on their exam, they could repeat the exam until a threshold of success was achieved. After two failed attempts, students were given additional time in the tutoring center or lab, one-on-one work with a tutor, or additional worksheets or homework to learn concepts that were missed on the exam. Retesting was designed to reduce anxiety for students and increase success and persistence. All students were required to take a comprehensive final exam, although no mastery was required on the final and only one attempt was provided. Study guides for the final exam, along with answer keys, were distributed to students for practice.

All software was available to the students outside of the classroom. Open lab times in the classroom were specific for developmental students only and available during non-class times. Students who missed class could make up the class time in this open lab setting. Students enrolled in the emporium model could pay for one course, finish the course, and complete the next course free in the same semester. Attendance was required and was part of the students' final participation grade but was not collected for this study.

\section{Face-to-face and online courses}

Traditional FtF and online courses had a similar structure, regarding content, assessments, and timelines, but mastery of content was not a requirement before learning new content. That meant that students could attempt quizzes without doing homework or skip homework or quizzes altogether and still continue. At the instructors' discretion, students could be penalized for turning in work past the mandated due dates, but that data could not be tracked. Both online and FtF formats had mandated common comprehensive final exams that were proctored and similar to that in the emporium sections. Starting in fall 2018, all online and traditional $\mathrm{FtF}$ courses received common periodic exams that also required proctored testing facilities to improve course consistency. These exams were comprised of the same questions from the emporium courses, though combined into exams that covered more topics as non-emporium students were tested less frequently. For example, in the emporium course, a proctored exam was given after every module. In the $\mathrm{FtF}$ and online sections, proctored exams were given after every two to three modules with the same number of questions (i.e., 20 to 25 questions). To combat fraud in online courses, the participating college initially purchased Biosig-ID from Biometric. By fall 2018 , this service was no longer available to online courses, and all students were required to come to campus or other approved location to take proctored exams. Traditional FtF courses were provided in one, two, or three-day a week sessions with homework and online quizzes completed mostly at home. Some faculty in these courses, who were in computer labs, allowed students to spend a limited amount of time in class working on assessments. In online courses, the use of online classroom support and instruction varied by instructor. Some professors held synchronous meeting times, some allowed for makeups for each exam, while still others used discussion boards to facilitate interaction with students. A few online instructors included practice exams as part of their courses as well.

\section{RESEARCH QUESTIONS}

This study compared final exam grades, course grades, and persistence of students enrolled in DM emporium style courses with those in corresponding FtF and online courses at a mid-sized, suburban community college in Northeastern United States. It was hypothesized that students who successfully 
passed an emporium DM course would perform equally well or better, as measured by their final exam and course grade, as students who completed the same course in a FtF or online modality. We also hypothesized that emporium students would persist in mathematics at the college in equal or higher percentages than those in FtF or online courses. The research questions were:

1. For students enrolled in DM courses, to what extent did differences exist between final exam grade by course modality?

2. For students enrolled in DM courses, to what extent did differences exist between student success rates by course modality?

3. For students enrolled in Math 020 and Math 026, to what extent did differences exist between persistence rates in mathematics by course modality?

\section{METHOD}

This was a retrospective, nonexperimental study. Students could choose to register for their DM course based on emporium (math lab with mastery experience), traditional FtF, or online formats. All DM course grades counted toward GPA at the participating college.

\section{Selection of Participants}

The sampling method was a purposeful convenience sample conducted in a retrospective manner. The participating community college was selected because (1) the lead researcher was employed at the college (i.e., convenience), and (2) the college had diversity in terms of course structure and student population (i.e., purposeful). The sample was also purposeful in the sense that it was selected from students who had either been enrolled or were currently enrolled in a mathematics course, starting fall 2015 through spring 2019. To determine persistence, enrollment data for summer and fall 2019 were also collected. Data collected from the institutional research office included student enrollment in all mathematics courses along with course modality (i.e., emporium, FtF, online, and hybrid). Fall 2015 semester included Math 028, which was a FtF-only course that combined Math 022 and Math 026 . Once emporium courses were offered full-scale, this course was removed from the course offerings. Because not all students enrolled in Math 022 were required to complete additional coursework, persistence was limited to Math 020 (Pre-Algebra) and Math 026 (Intermediate Algebra).

Of the total number of DM students, 4,606 (47.7\%) enrolled in FtF sections, 2,891 (29.9\%) enrolled in emporium sections, and 2,161 (22.4\%) enrolled in online sections. Ethnicity and gender of students in DM courses followed the same pattern as the overall college demographics with the largest representative group being White students $(46.0 \% ; n=4,447)$ followed by Hispanic $(26.9 \% ; n=2,597)$ and Black students $(19.9 \% ; n=1,918)$. Overall, more female students were placed into DM courses than male students $(61.9 \% ; n=5,974)$; average age was 24.77 years. Almost half of the students in the sample ranged in age from 18 to $20(48.3 \%)$.

\section{Final Exam}

In each DM course, student achievement was assessed by scores from a 40 multiple-choice item comprehensive common final exam and final course grade. Final exams were created by a faculty subcommittee that focused on DM redesign. The content of the exams followed the course objectives set forth by the mathematics department in Pre-Algebra, Elementary Algebra, and Intermediate Algebra. Across all semesters in this study and, regardless of learning modality, the final exam was the same and was mandated as the post-test for each course. The final exam was administered using an online commercial software program, but the numbers were algorithmically generated. Homework and quiz assessments were the same for all course modalities, but the course structure differed for the emporium courses. 
Table 1. Research Questions

\begin{tabular}{|c|c|c|c|c|c|c|}
\hline Research Question: To what extent: & DV & $\begin{array}{l}\text { Data } \\
\text { Type }\end{array}$ & IV & Defined & $\begin{array}{l}\text { Data } \\
\text { Type }\end{array}$ & Analysis \\
\hline $\begin{array}{l}\text { 1) were there differences in final exam } \\
\text { grade by the course modality of the } \\
\text { developmental mathematics course? }\end{array}$ & Final exam grade & Interval & $\begin{array}{l}\text { Course } \\
\text { Modality }\end{array}$ & $\begin{array}{l}\text { “0" = E, } \\
\text { "1" = FtF, } \\
\text { " } 2 "=\mathrm{O}\end{array}$ & Cat & $\begin{array}{c}\text { ANOVA } \\
\text { /Kruskal- } \\
\text { Wallis }\end{array}$ \\
\hline $\begin{array}{l}\text { 2) were there differences in final course } \\
\text { grade by the course modality of the } \\
\text { developmental mathematics course for } \\
\text { Math 020, Math 022, and Math } 026 \\
\text { students? }\end{array}$ & $\begin{array}{l}\text { Developmental Math Course Grade } \\
\text { A to C (pass), C- to F (fail), W } \\
\text { (withdrew) }\end{array}$ & Cat & $\begin{array}{l}\text { Course } \\
\text { Modality }\end{array}$ & $\begin{array}{l}\text { “0” = E, } \\
\text { "1" = FtF, } \\
\text { “2" = O }\end{array}$ & Cat & $\begin{array}{l}\text { Chi- } \\
\text { Square }\end{array}$ \\
\hline $\begin{array}{l}\text { 3A) were there differences in persistence } \\
\text { to the next mathematics course by } \\
\text { course modality of Math } 020 \text { or Math } 026\end{array}$ & $\begin{array}{l}\text { Persistence ("0" persisted and " } 1 \text { " not } \\
\text { persisted) }\end{array}$ & Cat & $\begin{array}{l}\text { Course } \\
\text { Modality }\end{array}$ & $\begin{array}{l}\text { “0” = E, } \\
\text { “1" = FtF, } \\
\text { " } 2 "=\mathrm{O}\end{array}$ & Cat & $\begin{array}{l}\text { Chi- } \\
\text { Square }\end{array}$ \\
\hline $\begin{array}{l}\text { 3B) were there differences in persistence } \\
\text { to the next mathematics course by } \\
\text { course modality of Math } 020 \text { or Math } 026\end{array}$ & $\begin{array}{l}\text { Persistence (“ } 0 \text { " persisted \& passed, } \\
\text { " } 1 \text { " failed/withdrew but persisted “2" } \\
\text { passed but not persisted, “ } 3 \text { " } \\
\text { failed/withdrew but not persisted) }\end{array}$ & Cat & $\begin{array}{l}\text { Course } \\
\text { Modality }\end{array}$ & $\begin{array}{l}\text { “0” = E, } \\
\text { “1” = FtF, } \\
\text { “2” = O }\end{array}$ & Cat & $\begin{array}{l}\text { Chi- } \\
\text { Square }\end{array}$ \\
\hline
\end{tabular}

Note. Cat = Categorical; $\mathrm{E}$ = Emporium; $\mathrm{O}$ = Online; FtF = Face-to-Face; $\mathrm{DV}$ = dependent variable; $\mathrm{IV}$ = independent variable.

\section{Procedures and Research Design}

Archival student data were retrieved from the Office of Institutional Research at this community college. Data collected included the following student information: (a) student's ID (generated by the colleges Institutional Research to protect privacy), (b) gender, (c) race, (d) mathematics course name, (e) course section number, (f) mathematics course grade, (g) course semester, and (h) course year. Data for final exams was generated by the math lab manager from the online homework platform and included: (a) course year, (b) course name, (c) course section, and (d) final exam grade.

Students who completed a DM course could receive either an "F, D, D+, or C-" as a failing grade, "A, $\mathrm{A}-, \mathrm{B}+, \mathrm{B}, \mathrm{B}-, \mathrm{C}+$, or $\mathrm{C}$ " for a passing grade, " $\mathrm{W}$ " for a withdrawal, "I" for incomplete, and a "AZ, BZ, or $C Z$ " for passing via testing out. Because instructors were not required to report plus and minus grades, final course grade was categorized as passing ( $\mathrm{C}$ or higher), failing (C-, D or F), or W (withdrawal). All incompletes and grades with a " $Z$ " were removed because of the small sample size. Students who repeated a course were marked specifically for tracking persistence and completion. Modality was coded as three categories: emporium, FtF, or online. Separate analyses by DM course level were conducted for final exam grade, final course grade, and persistence by course modality.

\section{Variables and Data Analysis}

Persistence in mathematics was first coded as a dichotomous variable and then as a categorical variable. Persistence, as a dichotomous variable, was coded as a " 0 " = persisting in mathematics and a " 1 " = not persisting for a student that did not continue in mathematics during the data time period. The categorical persistence variable was coded as a "1" = passed the course and persisted to the next math course, " 2 " = failed or withdrew but retook the mathematics course, " 3 " = passed their course but did not take another mathematics course, and " 4 " failed or withdrew from their course and did not retake the course. For this analysis, grades were coded as "Passing" if a student earned an A, B, or C, "Failing" if a student earned a C-, D, or F and "Withdrawn" if a student withdrew before the drop date during the 14th week of the semester. Table 1 contains variables, data type, and analysis conducted by research question.

All analyses were conducted with the Statistical Package for the Social Sciences v. 25. The grouping variable for all three questions was course modality (i.e., emporium, FtF, and online). To determine if statistically significant differences existed between mean final exam scores by course modality, an 
Table 2. Results for Final Exam Scores Based on Course Modality

\begin{tabular}{|c|c|c|c|c|c|c|c|c|}
\hline & \multirow[b]{2}{*}{$N$} & \multirow[b]{2}{*}{$M$} & \multirow[b]{2}{*}{$S D$} & \multirow[b]{2}{*}{ Md } & \multicolumn{2}{|c|}{$95 \% \mathrm{CI}$} & \multirow[b]{2}{*}{ Min } & \multirow[b]{2}{*}{$\operatorname{Max}$} \\
\hline & & & & & $L L$ & UL & & \\
\hline Emporium & 1830 & 77.88 & 13.46 & 80.00 & 77.26 & 78.50 & .00 & 100.00 \\
\hline Face-to-Face & 1430 & 69.71 & 17.49 & 72.50 & 68.80 & 70.62 & .00 & 101.00 \\
\hline Online & 660 & 68.63 & 19.12 & 70.63 & 67.16 & 70.09 & .00 & 100.00 \\
\hline Total & 3920 & 73.34 & 16.61 & 75.50 & 72.82 & 73.86 & .00 & 101.00 \\
\hline
\end{tabular}

Note. $M=$ Mean; $S D=$ Standard deviation; $M d=$ Median; $L L=$ Lower limit; $U L=$ Upper limit.

Table 3. Final Exam Scores and Percentage of Students Taking Final Exam by Modality by Academic Year (AY) and Course

\begin{tabular}{|c|c|c|c|c|c|c|}
\hline \multirow[b]{3}{*}{ Modality by Year } & \multicolumn{6}{|c|}{ Final Exam } \\
\hline & \multicolumn{2}{|c|}{ Math 020} & \multicolumn{2}{|c|}{ Math 022} & \multicolumn{2}{|c|}{ Math 026} \\
\hline & Average & Completers & Average & Completers & Average & Completers \\
\hline \multicolumn{7}{|l|}{ Emporium } \\
\hline AY $2015-2016$ & 86.42 & $32.0 \%(n=157)$ & 75.99 & $44.0 \%(n=218)$ & 81.08 & $23.0 \%(n=115)$ \\
\hline AY 2016- 2017 & 81.64 & $26.0 \%(n=152)$ & 74.13 & $45.0 \%(n=265)$ & 78.75 & $28.0 \%(n=165)$ \\
\hline AY 2017- 2018 & 82.79 & $19.0 \%(n=106)$ & 75.93 & $46.0 \%(n=250)$ & 76.54 & $33.0 \%(n=183)$ \\
\hline AY $2018-2019$ & 81.95 & $21.0 \%(n=101)$ & 74.85 & $50.0 \%(n=240)$ & 73.80 & $28.0 \%(n=135)$ \\
\hline \multicolumn{7}{|l|}{ Face-to-Face } \\
\hline AY $2015-2016$ & 76.04 & $31.3 \%(n=126)$ & 68.91 & $31.3 \%(n=126)$ & 68.55 & $37.3 \%(n=150)$ \\
\hline AY 2016- 2017 & 73.75 & $34.9 \%(n=133)$ & 64.74 & $29.1 \%(n=111)$ & 69.35 & $36.0 \%(n=137)$ \\
\hline AY 2017- 2018 & 72.91 & $32.5 \%(n=148)$ & 68.34 & $31.3 \%(n=143)$ & 70.93 & $36.2 \%(n=165)$ \\
\hline AY 2018- 2019 & 74.47 & $32.9 \%(n=116)$ & 69.62 & $38.8 \%(n=137)$ & 71.55 & $28.3 \%(n=100)$ \\
\hline \multicolumn{7}{|l|}{ Online } \\
\hline AY 2015- 2016 & 83.07 & $23.7 \%(n=41)$ & 64.30 & $52.0 \%(n=90)$ & 67.07 & $24.3 \%(n=42)$ \\
\hline AY 2016- 2017 & 79.98 & $24.7 \%(n=56)$ & 64.95 & $46.3 \%(n=105)$ & 66.23 & $29.1 \%(n=66)$ \\
\hline AY 2017- 2018 & 73.73 & $30.3 \%(n=70)$ & 63.15 & $44.2 \%(n=102)$ & 67.06 & $25.5 \%(n=59)$ \\
\hline AY 2018- 2019 & 74.74 & $27.1 \%(n=39)$ & 72.87 & $39.6 \%(n=57)$ & 69.28 & $33.3 \%(n=48)$ \\
\hline
\end{tabular}

ANOVA was planned. However, the $p$ value from the Levene's test was less than .05 , which indicated the assumption of homogeneity of variance was violated, and the non-parametric Kruskal-Wallis test was conducted. Final exam grade was measured at an interval level. Statistical significance was chosen a priori as using an alpha of .05 .

Chi-square tests were conducted to answer questions two and three, which had a categorical dependent variable and categorical independent variable. Interpretations of the magnitude of the Cramer's V effect size (ES) vary by degrees of freedom (Kim, 2017). In accordance with recommendations in the literature, based on the degrees of freedom in this study, Cramer's V ES was considered small at the .05 level (small), somewhat noteworthy at the .15 level (medium), and noteworthy at the .25 level (large; see Kim 2017).

\section{RESULTS}

\section{Research Question 1: Final Exam Grade by Course Modality}

Descriptive statistics are presented in Table 2. Average final exam grades per course modality and course type by academic year are presented in Table 3. Approximately 50\% of all DM students completed their course to the final exam. The first research question looked at the extent to which that there were differences in the common final exam grade by course modality in DM programs. The homogeneity of variance assumption was not met $(p<.05)$. Therefore, a non-parametric Kruskal-Wallis test was conducted. For the emporium modality, $95 \%$ confidence intervals of the means for the final exam did not overlap the confidence intervals for FtF and online courses. As shown in Table 2, the lower limit for emporium courses was seven points higher than the upper limit for both FtF and online courses. Table 3 contains the average exam grades disaggregated by course level and modality. 
Table 4. Descriptive Statistics for Developmental Mathematics Course Grade

\begin{tabular}{|c|c|c|c|c|c|c|c|c|c|}
\hline \multirow[b]{4}{*}{ Success } & \multicolumn{3}{|c|}{ Math 020} & \multicolumn{3}{|c|}{ Math 022} & \multicolumn{3}{|c|}{ Math 026} \\
\hline & $\mathrm{FtF}$ & $\mathrm{E}$ & $\mathrm{O}$ & $\mathrm{FtF}$ & $\mathrm{E}$ & $\mathrm{O}$ & $\mathrm{FtF}$ & $\mathrm{E}$ & $\mathrm{O}$ \\
\hline & $n=$ & $n=$ & $n=$ & $n=$ & $n=$ & $n=$ & $n=$ & $n=$ & $n=$ \\
\hline & 895 & 1255 & 578 & 909 & 1962 & 938 & 1000 & 1417 & 642 \\
\hline \multirow[t]{2}{*}{ Passed } & 549 & 605 & 237 & 521 & 1131 & 278 & 578 & 756 & 231 \\
\hline & $61.3 \%$ & $48.2 \%$ & $41.0 \%$ & $57.3 \%$ & $57.6 \%$ & $29.6 \%$ & $57.8 \%$ & $53.4 \%$ & $36.0 \%$ \\
\hline \multirow[t]{2}{*}{ Failed } & 188 & 240 & 137 & 237 & 342 & 374 & 228 & 292 & 177 \\
\hline & $21.0 \%$ & $19.1 \%$ & $23.7 \%$ & $26.1 \%$ & $17.4 \%$ & $39.9 \%$ & $22.8 \%$ & $20.6 \%$ & $27.6 \%$ \\
\hline \multirow[t]{2}{*}{ Withdrew } & 158 & 410 & 204 & 151 & 489 & 286 & 194 & 369 & 234 \\
\hline & $17.7 \%$ & $32.7 \%$ & $35.3 \%$ & $16.6 \%$ & $24.9 \%$ & $30.5 \%$ & $19.4 \%$ & $26.0 \%$ & $36.4 \%$ \\
\hline
\end{tabular}

Note. $\mathrm{FtF}=$ Face-to-Face; $\mathrm{E}=$ Emporium; $\mathrm{O}=$ Online.

There was a statistically significant difference between groups on final exam scores for Math 020, $\chi^{2}(2, n=1130)=109.986, \rho<.001$, for Math 022, $\chi^{2}(2, n=1613)=125.998, \rho<.001$, and for Math $026, \chi^{2}(2, n=1177)=85.547, \rho<.001$. The mean rank final exam score was 1699.48 for FtF courses, 2272.50 for emporium courses and 1660.95 for online courses and eta squared ES of .0666 (see Tomczak \& Tomczak, 2014). The median final exam course grades were 80.00 for emporium courses, 70.63 for online courses, and 72.5 for FtF courses. The percentage of students who took the final exam was generally highest in Math 022 although the final exams were highest on average for emporium students across all courses.

\section{Research Question 2: Final Course Grade by Course Modality}

Chi-square results indicated that statistically significant differences existed between course modality and final course grade for Math $020, \chi^{2}(4, n=2728)=90.383, \rho<.001$, with a small Cramer's V ES of .129 , for Math 022, $\chi^{2}(4, n=3809)=274.117, \rho<.001$, with a noteworthy just above medium threshold Cramer's V ES of .190, and for Math 026, $\chi^{2}(4, n=3059)=91.880, \rho<.001$, with a small Cramer's V ES of .123. In Math 020, pass rates were $61.3 \%$ for FtF courses, $48.2 \%$ for emporium courses, and $41.0 \%$ for online courses. As seen in Table 4, pass rates in Math 022 and Math 026 were comparable for FtF and emporium courses and lower and for online courses. Students in online courses withdrew and failed at higher rates.

\section{Research Question 3A: Dichotomous Persistence by Modality}

Chi-square results for Math 020 indicated that statistically significant differences existed on persistence in mathematics by course modality at the $p<.05$ level when persistence was measured as a dichotomous variable, $\chi(2)=6.893, p=.032$, with a small Cramer's V ES of .050. Math 020 students in FtF courses persisted $66.8 \%$ of the time compared to $65 \%$ in emporium and $60.2 \%$ in online courses. As seen in Table 5, differences were related to lower persistence rates in Math 020 online courses. For Math 026, no statistically significant differences existed on persistence in mathematics by course modality at the $p<$ .05 level when persistence was measured as a dichotomous variable, $\chi(2)=.183, p=.913$, Cramer's V $\mathrm{ES}=.008$. Overall, students in Math 026 persisted at high rates and those rates were approximately the same percentage across course modality.

\section{Research Question 3B: Categorical Persistence by Modality}

Statistically significant differences existed by the persistence category that considered success measures (i.e., pass, fail, or withdrew) by course modality for students enrolled in Math 020, $\chi(6)=67.346, p<$ .001 , Cramer's V ES=.111. As seen in Table 5, persistence rates for students who also passed the course were highest for the FtF Math 020 students. Statistically significant differences also existed by persistence category that considered success measures (i.e., pass, fail, or withdrew) by course modality for students who enrolled in Math 026, $\chi(6)=97.878, p<.001$, Cramer's V ES $=.126$. Differences were related to online courses. While students in different modalities appeared to persist at around the rate 
Table 5. Persistence by Congruence of Modality for Math 020 and Math 026

\begin{tabular}{|c|c|c|c|c|c|c|}
\hline & \multicolumn{3}{|c|}{ Math 020} & \multicolumn{3}{|c|}{ Math 026} \\
\hline & $\mathrm{FtF}$ & $E$ & $\mathrm{O}$ & $\mathrm{FtF}$ & $\mathrm{E}$ & $\mathrm{O}=$ \\
\hline & $n=895$ & $n=1255$ & $n=578$ & $n=1000$ & $n=1417$ & $n=642$ \\
\hline \multirow[t]{2}{*}{ Persisted } & 598 & 816 & 348 & 830 & 1169 & 534 \\
\hline & $66.8 \%$ & $65.0 \%$ & $60.2 \%$ & $83.0 \%$ & $82.5 \%$ & $83.2 \%$ \\
\hline \multirow[t]{2}{*}{ Not Persisted } & 297 & 439 & 230 & 170 & 248 & 108 \\
\hline & $33.2 \%$ & $35.0 \%$ & $39.8 \%$ & $17.0 \%$ & $17.5 \%$ & $16.8 \%$ \\
\hline \multirow[t]{2}{*}{ Pa \& P } & 430 & 480 & 180 & 502 & 692 & 206 \\
\hline & $48.0 \%$ & $38.2 \%$ & $31.1 \%$ & $50.2 \%$ & $48.8 \%$ & $32.1 \%$ \\
\hline \multirow[t]{2}{*}{$\mathrm{F} / \mathrm{W} \& \mathrm{P}$} & 168 & 336 & 168 & 328 & 477 & 328 \\
\hline & $18.8 \%$ & $26.8 \%$ & $29.1 \%$ & $32.8 \%$ & $33.7 \%$ & $51.1 \%$ \\
\hline \multirow[t]{2}{*}{ Pa \& NP } & 119 & 125 & 57 & 76 & 64 & 25 \\
\hline & $13.3 \%$ & $10.0 \%$ & $9.9 \%$ & $7.6 \%$ & $4.5 \%$ & $3.9 \%$ \\
\hline \multirow[t]{2}{*}{ F/W \& NP } & 178 & 314 & 173 & 94 & 184 & 83 \\
\hline & $19.9 \%$ & $25.0 \%$ & $29.9 \%$ & $9.4 \%$ & $13.0 \%$ & $12.9 \%$ \\
\hline
\end{tabular}

Note: FtF = Face-to-Face; E = Emporium; O = Online; Pa \& P = Passed \& Persisted; F/W \& P = Failed/Withdrew but Persisted; Pa \& $\mathrm{NP}=$ Passed but Not Persisted; F/W \& NP = Failed/Withdrew but Not Persisted.

of students in Math 026, when disaggregated further, persistence rates of students who passed were $50.2 \%$ in FtF courses, $48.8 \%$ in emporium courses, and $32.1 \%$ in online courses. However, students who failed or withdrew in an online course for Math 026 were more likely to persist in mathematics $(51.1 \%)$ than students who failed in a FtF course $(32.8 \%)$ or emporium course $(33.7 \%)$.

\section{DISCUSSION}

Conversations within and among institutions of higher education have focused on how to increase graduation rates while decreasing time to degree completion. These graduation rates are a measure of accountability and evaluation of institutional performance. Community colleges have been faced with the challenge of reducing time to degree completion for a large population of students who need academic remediation. Emporium models were introduced as one method for accelerating students' remediation as an alternative to completing semester-long remedial courses offered in developmental education programs (National Center for Academic Transformation, 2014). The main message from this study was that, except for students who are placed in pre-algebra content, emporium courses are viable options for accelerating students through a DM course sequence. It should be noted that emporium courses in this study were designed to provide the needed support and access to tutors and instructors. Results indicated that (a) final course grades and persistence were similar for students in emporium and FtF courses, except in the lower-level course and (b) students who chose to enroll in online courses were not as successful in the course. The viability of final exam scores as a measure of student success should be questioned given that success rates in FtF courses were higher than emporium models in Math 020 and Math 026 but final exam scores were lower.

\section{Student Success Rates by Course Modality}

In response to a national call to increase students' access to and increase success in college-level mathematics, the participating college's mathematics faculty agreed that offering courses that allow students to accelerate through course material they had already mastered could increase student success and persistence. Accordingly, in fall 2015, the college began offering FtF, online, and emporium course modalities. Emporium, as a course modality, was promoted at conferences and by publishers as an option for accelerating students through remedial content and, consequently, more quickly enter college-level courses. A strength of emporium courses is that students can accelerate through the course by skipping previously mastered materials; thus, they possibly can finish the course in one semester rather than multiple semesters. 


\section{Final Exam Scores}

Final exam grades were examined because they serve as a measure of knowledge learned throughout the course. However, there are limitations to using this one-time score in a study. Students' decision to invest time in studying for the final might depend on their current grade. For example, a student who has a low $C$ average, but can maintain a passing grade with a low final exam score, might invest less energy into studying for the final exam. Contrarily, a student who has a high $C$ and can earn a B if they do well on the final might invest a lot of time studying for the final exam. Perhaps that explains why statistically significant differences existed by course modality. Across all three courses, emporium students scored higher on the common final exam even though passing rates in emporium courses were similar in the upper two FtF courses and lower in the lowest level course. The emporium structure promoted mastery learning through frequent assessments and required grade benchmarks that had to be met throughout the course; thus, emporium students had been working under the mentality that mastery was required. Students in emporium courses knew that in order to succeed, they had to work to mastery benchmarks throughout the semester. Although self-efficacy was not measured, we hypothesized that the mastery experiences might result in increased mathematics self-efficacy (Zientek et al., 2019) and higher scores on the final exam. For several academic years, students enrolled in emporium sections scored approximately five to 10 percentage points higher on the final exam than those enrolled in a FtF or online courses. Students in Math 020 emporium sections scored an average final exam grade of $83.2 \%$ but passed their respective course only $48.2 \%$ of the time compared with the average final exam scores of $\mathrm{FtF}(74.3 \%)$ and online $(77.9 \%)$ who passed at $61.3 \%$ and $41.0 \%$ respectively. Regardless, as seen in Table 3, students benefited in the emporium course on a culminating test, which corroborated findings by Cousins-Cooper et al. (2017). Future studies could consider differences by withdrawal rates.

\section{Final Course Grades}

Statistically significant differences also existed by course modality in the final course grade, but these differences appeared to be primarily because of lower pass rates and higher withdrawal rates in the online courses as seen in Table 4. Efforts are underway to further improve student success in online courses, including employing measures of demonstrated mastery of content at multiple levels and limiting the number of students who take online DM courses. Starting with fall 2019, enrolling in an online mathematics course required an application process, and only students with experience in online education or with documented work or family obligations qualified for an online course. Differences in withdrawal rates might also stem from the institutional policy. Emporium students were encouraged to withdraw closer to the end of the course so that they could pick up where they left off in the following semester. This policy was not available for the other modalities and helped emporium students with their GPAs by allowing them to continue to accelerate if they chose the same modality the following semester. This could explain higher values in withdrawal rates seen in Table 4.

\section{Lowest-level courses}

For the lower course, students seem to benefit more from FtF courses. This seems logical because they might not have the discipline or confidence to work independently on mathematics topics, particularly when they needed remediation on more topics than students in higher-level courses. One hypothesis is that students with minimal understanding of basic pre-algebra concepts need more supports to learn that material. Given that Bickerstaff et al. (2016) found accelerated courses may be too fast for some students, it might be that these students in the lowest-level course could not keep up with a pace in an emporium model.

\section{Emporium courses}

Reasons for success rates in emporium courses in Math 022 and Math 026 that mirrored success rates in FtF courses might be because of (a) the well-defined emporium program (Saxon \& Martirosyan, 2017) 
along with high-quality FtF classrooms and (b) the opportunity for students to choose their course modality. Another unique practice in this study was that in emporium courses students initially took an exam on the first day based on the previous courses learning outcomes, which may have helped in placement accuracy. In addition, best practices were applied that dealt with prompt feedback, interaction with faculty, and high expectations (Chickering \& Gamson, 1987). Emporium students had to demonstrate mastery on topics and, thus, received success at frequent intervals during the semester. Successful students had to demonstrate that they could monitor their progress and timelines, albeit some timelines were established within the course structure. When unsuccessful, emporium students were provided resources to improve their ability to succeed and were required to meet with faculty or a tutor before proceeding. Thus, emporium is a viable acceleration option for many students.

\section{Persistence in Mathematics by Course Modality}

Persistence in mathematics was limited to upper and lower-level courses because not all students in the middle level were required to complete a subsequent mathematics course. As seen in Table 5, persistence was similar for the emporium and FtF sections in Math 020 and similar across all three course structures in Math 026. When focusing within each modality, 020 students who passed their FtF persisted at higher rates than other modalities; persistence was similar for FtF and emporium 026 students.

Similarity in success and persistence in mathematics rates for emporium and FtF courses, particularly for the upper-level courses supported results by Cousins-Cooper et al., (2017) who found pass rates (grades A through C) between emporium and lecture courses were not statistically significantly different. Ashby et al. (2011) noted in their study that success may be related to the learning environment and whether attrition was considered. A challenge in this study was that the sample was not restricted to first-time enrolled freshmen, thereby giving them a slight advantage in regard to academic and emotional maturity. More attention should be given to the early entry-level skills of students who are placed into the lowest-level course.

\section{Limitations}

A limitation of this study was that it was conducted at one institution in the Northeast. Another constraint worth noting is that student transfers between colleges could not be tracked. This study was also limited in that the teachers for each course varied each year; no determination could be made if a faculty member influenced the learning or success of a course. Any small refinements that were made to the course structure each year were not tracked or evaluated for their influence on student success and persistence which created an additional limitation. A final limitation is that the results are biased towards those that persisted.

\section{Implications and Further Research}

This study can inform educators about the success and persistence rates of students in DM courses after the adoption of an emporium modality. Findings from this study suggest that an emporium model that requires mastery benchmarks, proctored exams, in-class tutors, an in-class instructor, additional placement confirmation, and retesting is a viable option for accelerating students through the DM course sequence when students' remediation is not extensive (i.e., placed above pre-algebra). Students in the lowest-level DM course who are not near the cut-off placement score for the next course should enroll in a traditional FtF pre-algebra course with an option to accelerate in the emporium model after gaining pre-algebra skills.

Pass rates were still lower than desired. Even though emporium options appear to accelerate more DM students enrolled in upper- and middle-level courses, at least $40 \%$ of students were not successful across course level and course modality. These findings suggest that increasing success in DM courses will require more than changes in delivery models or additions of mastery benchmarks. The mathematical education community has embraced the need to change the curricula and teaching methods in 
mathematics courses to a model that focuses both on conceptual understanding and procedural fluency (National Council of Teachers of Mathematics, 2000). The need for encouraging reasoning and understanding was supported by the Stigler et al. (2010) study that found DM students tended to rely on a faulty recollection of when and how to apply procedures. While Stigler et al. (2010) described DM students' understanding of concepts as both weak and fragile, they found reason for hope in the fact that (a) students could be coaxed into reasoning by asking appropriate questions followed by allowing students license to reason instead of approaching problems duplicating the method they were taught and (b) "when students are able to provide conceptual explanations, they also produce correct answers" (p. 13). Thus, students who are failing across modalities need an intervention that addresses comprehension of mathematical concepts and procedural fluency, in addition to the socio-cognitive and motivation constructs.

Continued research and tracking of student success and progression through to a degree program is also recommended, along with tracking reasons for why students withdrew. It behooves administrators to focus on the retention of the students they have for continued growth and sustainability. Knowing where and why students are failing or dropping out, especially in mathematics, can lead to identifying the factors that are controllable by the college to create interventions that improve the outcomes of success and persistence.

Author contributions: All authors were involved in concept, design, collection of data, interpretation, writing, and critically revising the article. All authors approve final version of the article.

Funding: The authors received no financial support for the research and/or authorship of this article.

Declaration of interest: Authors declare no competing interest.

Data availability: Data generated or analysed during this study are available from the authors on request.

\section{REFERENCES}

Ashby, J., Sadera, W. A., \& McNary, S. W. (2011). Comparing student success between developmental math courses offered online, blended and face-to-face. Journal of Interactive Online Learning, 10(3), 128-140.

Bahr, P. R. (2008). Does mathematics remediation work? A comparative analysis of academic attainment among community college students. Research in Higher Education, 49, 420-450. https://doi.org/10.1007/s11162-008-9089-4

Bailey, T., Jeong, D. W., \& Cho, S. W. (2010). Referral, enrollment, and completion in developmental education sequences in community colleges. Economics of Education Review, 29(2), 255-270. https://doi.org/10.1016/j.econedurev.2009.09.002

Bickerstaff, S., Fay, M. P., \& Trimble, M. J. (2016). Modularization in developmental mathematics in two states: Implementation and early outcomes (CCRC Working Paper No. 87). Community College Research Center, Teachers College, Columbia University.

Braun, B., Bremser, P., Duval, A. M., Lockwood, E., \& White, D. (2017). What does active learning mean for mathematics? Notice of the AMS, 64(2), 124-129. https://doi.org/10.1090/noti1472

Cafarella, B. (2016). Acceleration and compression in developmental mathematics: Faculty viewpoints. Journal of Developmental Education, 39(2), 12-25.

Cafarella, B. V. (2014). Exploring best practices in developmental math. Research E Teaching in Developmental Education, 30(2), 3564.

Chen, X., \& Simone, S. (2016). Remedial coursetaking at U.S. public 2-and 4-year institutions: Scope, experiences, and outcomes. National Center for Education Statistics, U.S. Department of Education. https://nces.ed.gov/pubs2016/2016405.pdf

Chickering, A. W., \& Gamson, Z. F. (1987). Seven principles for good practice in undergraduate education. Washington Center News. http://www.lonestar.edu/multimedia/sevenprinciples.pdf

Cousins-Cooper, K., Staley, K. N., Kim, S., \& Luke, N.S. (2017). The effect of the math emporium instructional method on students' performance in college algebra. European Journal of Science and Mathematics Education, 5(1), 1-13. https://doi.org/10.30935/scimath/9493

Fain, P. (2011, December 23). Letting go of lecture. Inside Higher Ed. https://www.insidehighered.com/news/2011/12/23/montgomery-college-follows-remedial-math-revolution

Kim, H. Y. (2017). Statistical notes for clinical researchers: Chi-squared test and Fisher's exact test. Restorative Dentistry $\mathcal{E}$ Endodontics, 42(2), 152-155. https://doi.org/10.5395/rde.2017.42.2.152

Lucas, M. S., \& McCormick, N. J. (2007). Redesigning mathematics curriculum for underprepared college students. The Journal of Effective Teaching, 7(2), 36-50.

Mesa, V., Celis, S., \& Lande, E. (2014). Teaching approaches of community college faculty: Do they relate to classroom practices? American Educational Research, 51(1), 117-151. https://doi.org/10.3102/0002831213505759 
National Center for Academic Transformation. (2014). How to redesign a developmental math program using the emporium model. http://www.thencat.org/Guides/DevMath/DMChapterI.html

National Council of Teachers of Mathematics. (2000). Principles and standards for school mathematics. Author.

Nguyen, T. (2015). The effectiveness of online learning: Beyond no significant difference and future horizons. MERLOT Journal of Online Learning and Teaching, 11(2), 309-319.

Ni, A. Y. (2013). Comparing the effectiveness of classroom and online learning: Teaching research methods. Journal of Public Affairs Education, 19(2), 199-215. https://doi.org/10.1080/15236803.2013.12001730

Northern Virginia Community College. (2020). Developmental math program. https://www.nvcc.edu/academics/developmental/math.html

Rutschow, E. Z., \& Schneider, E. (2011, June). Unlocking the gate: What we know about improving developmental education. http://www.mdrc.org/sites/default/files/full_595.pdf

Saxon, D. P., \& Martirosyan, N. M. (2017). Improving accelerated developmental mathematics courses. Journal of Developmental Education, 41(1), 24-27.

Stigler, J. W., Givvin, K. B., \& Thompson, B. J. (2010). What community college developmental mathematics students understand about mathematics. MathAMATYC Educator, 1(3), 4-16.

Taylor, J. M. (2008). The effects of a computerized-algebra program on mathematics achievement of college and university freshmen enrolled in a developmental mathematics course. Journal of College Learning and Reading, 39(1), 35-53. https://doi.org/10.1080/10790195.2008.10850311

Tomczak, M., \& Tomczak, E. (2014). The need to report effect size estimates revisited. An overview of some recommended measures of effect size. Trends in Sports Sciences, 1(21), 19-25.

Twigg, C. A. (2011). The math emporium: A silver bullet for higher education. Change: The Magazine of Higher Learning, 43(3), 2534. https://doi.org/10.1080/00091383.2011.569241

Usher, E. L., \& Pajares, F. (2009). Sources of self-efficacy in mathematics: A validation study. Contemporary Educational Psychology, 34(1), 89-101. https://doi.org/10.1016/j.cedpsych.2008.09.002

Xu, D., \& Jaggars, S. S. (2013). Examining the effectiveness of online learning within a community college system: An instrumental variable approach (Working Paper No. 56). http://ccrc.tc.columbia.edu/media/k2/attachments/examining-effectiveness-of-onlinelearning.pdf

Zientek, L. R., Fong, C. J., \& Phelps, J. M. (2019). Sources of self-efficacy of community college students enrolled in developmental mathematics. Journal of Further and Higher Education, 43(2), 183-200. https://doi.org/10.1080/0309877X.2017.1357071

Zimmerman, B. J. (1990). Self-regulated learning and academic achievement: An overview. Educational Psychologist, 25(1), 3-17. https://doi.org/10.1207/s15326985ep2501_2

Zimmerman, B. J. (2005). Chapter 2: Attaining self-regulation: A social cognitive perspective. In M. Boekaerts, P. Pintrich, \& M. Zeidner (Eds), Handbook of Self-regulation (pp. 13-39). Academic Press. 